\title{
Sulphate of potash and dipping time influence the seed germination and growth of pecan nuts
}

Muhammad Sajid ${ }^{1}$, Ijaz Hussain ${ }^{2 *}$, Abdur Rab ${ }^{1}$, Shah Masaud Khan ${ }^{2}$, Zubair Aman ${ }^{1}$, Syed Tanveer Shah ${ }^{1}$, Naveed Ahmad ${ }^{1}$ and Qazi Shoiab Ali $^{1}$

1. Department of Horticulture, The University of Agriculture Peshawar -Pakistan

2. Department of Agricultural Sciences, University of Haripur-Pakistan

*Corresponding author's email: ijazhorticulturist@gmail.com

\section{Citation}

Muhammad Sajid, Ijaz Hussain, Abdur Rab, Shah Masaud Khan, ZubairAman, Syed Tanveer Shah, Naveed Ahmad and Qazi Shoiab Ali. Sulphate of potash and dipping time influence the seed germination and growth of pecan nuts. Pure and Applied Biology. Vol. 6, Issue 1, pp310-316. http://dx.doi.org/10.19045/bspab.2017.60029

\begin{tabular}{llll}
\hline \hline Received: 23/11/2016 & Revised: 21/02/2017 & Accepted: 25/02/2017 & Online First: 28/02/2017 \\
\hline
\end{tabular}

\section{Abstract}

To investigate the influence of various levels of SOP and dipping time on seed germination and growth of pecan nuts, a study was carried out at Horticulture Department, Agriculture University Peshawar, Pakistan (during 2012). The experiment consists of SOP levels $(0,2,4,6,8 \& 10 \%)$ and dipping times $(5,10,15 \& 20$ hours $)$ respectively in order to find out the optimum level of SOP and best dipping time for successful germination and better growth of pecan nuts. The results revealed that SOP levels and dipping time significantly affected most of the parameters under study. The interactions between SOP and dipping time showed significant differences for all parameters except germination percentage, root length, leaf area plant ${ }^{-1}$, stem diameter. The pecan nuts treated with $10 \%$ SOP solution showed best result regarding, number of roots plant ${ }^{-1}(73.00)$, seedling height plant ${ }^{-1}(22.53 \mathrm{~cm})$, stem diameter plant ${ }^{-1}(0.63 \mathrm{~cm})$, root length $(61.67 \mathrm{~cm})$, germination percentage $(70.83 \%)$. The mean data for dipping time indicated that the pecan nuts dipped for 10 hours showed best results for number of roots plant $^{-1}(69.00)$, seedling height plant ${ }^{-1}(19.04 \mathrm{~cm})$, root length plant ${ }^{-1}(56.11 \mathrm{~cm})$, germination percentage $(65.00 \%)$, and. It was concluded from the experiment that SOP @ 10\% with 10 hours of dipping time gave best results in seed germination, seedling growth and establishment of pecan nuts plants under agro climatic conditions of Peshawar, Pakistan.

Keywords: Dipping times; Sulphate of potash; Pecan nuts; Germination

\section{Introduction}

Pecan is an important dry fruit botanically known as Caryaillinoinensis, belongs to family Juglandaceae. It is closely related to the walnut. Pecan is native to Central America. The word pecan is from an Algonquian, which means a nut that require a stone to crack. In USA, its growing states are Mississippi, New Mexico, Georgia, Texas, Albana, Louisiana, Oklahoma, Florida, North Carolina [1]. In Pakistan, pecan was first introduced in 1972. It has low chilling requirement, and easily grown in plain areas as compared to walnut. Uptill now 9 varieties 
of pecan are tested. Wichita variety can give about $13 \mathrm{~kg}$ nuts tree ${ }^{-1}[2]$. Pecan is medium to large sized deciduous tree ranging from 100-140 feet, with alternate leaves, pinnately compound. The pecan flowers are unisexual in nature; both sexes are found on the same tree in the form of separate clusters. The fruit is dark brown in color which is covered with yellow scales. The fruit is thin-shelled nuts; four winged from base to apex, borne in clusters of three to twelve. The husk is thin and brittle. The husk often persists on the branch into the winter after dropping the nut. The nut is pointed at both end having a thin shelled with a reddish-brown color. The pecan nut is very valuable economically as well as medicinally. Economically pecan nut is widely used in candies and cookies due to high percentage of fats. Due to its sweet and delicious taste it can be used in ice cream, cake and breads. The oil obtained from pecan nut is used in cooking and cosmetics. Medicinally the pecan is used for the curing of ringworm. Bark of pecan can be consumed for treatment of tuberculosis [3]. Pecan nuts also have been very effective in enhancing the results of a diet designed to lower the level of cholesterol. Nutritionally pecan is of prime importance as it contains vitamin A, Vitamin $\mathrm{E}$ and most of the vitamins that belong to vitamin B complex group; also, it is very rich source of Zinc and many important mineral elements. It is very helpful in cellular substrate metabolism as it provides important co enzymes for metabolism. In addition, the milk made from its seeds is usually added to season corn cake and soups for thickening. Effectiveness of priming depends upon the initial quality of the seed, which species are used, and conditions for treatment like water potential, temperature, duration, and other conditions associated with the priming medium [4]. Pecan rootstocks are mainly grown from already established seedlings that are sown in nursery for germination. But pecan nut has a problem of poor seed germination. This is also accompanied by a problem of irregular germination, as not all the seedlings emerge at the same time. Pecan nut began to germinate one to two month after sowing and usually it continues for four months or even longer than that. As a result a huge variation in seedling size and age can be observed, which result in variation in grafting time and the grafted plant too, are not uniform in size and age. Keeping in view the importance of the above mentioned problem the proposed study is designed as an attempt to study the "Effect of different levels of sulfate of potash and dipping time on seed germination and growth of pecan nut" with the objectives; To find out optimum level of SOP for seed germination and growth of pecan. Find out optimum dipping time in hours for seed germination of pecan. Investigate the best interactive effect of SOP and dipping time on seed germination and growth of pecan.

\section{Materials and methods}

\section{Experimental details and treatments}

An experiment entitled "Effect of different levels of sop (sulphate of potash) and dipping time on seed germination and growth of pecan" was conducted at Ornamental Nursery, Department of Horticulture, the University of Agriculture Peshawar, Pakistan during 2012.

\section{Experimental materials}

The seeds used for the experiment were healthy and disease free, and were procured from Agriculture Research Institute (ARI), Tarnab, Peshawar. Seeds were sown in plastic bags of medium size $(17 \times 11 \mathrm{~cm})$ available at Ornamental Nursery, Department of Horticulture, The University of Agriculture Peshawar. The media used was of garden soil, silt and clay $(1: 1: 1)$. The experimental design used for the study was Randomized Complete Block Design (RCBD) with two factors factorial arrangement. 
Factor A: Dipping time (Hours)

T1: 05 hours, T2: 10 hours, T3: 15 hours, T4: 20 hours.

Factor B: SOP (\%)

S0: 0\%, S1: 2\%, S2: 4\%, S3: 6\%, S4: $8 \%$, S5:10\%.

\section{Preparation of SOP}

SOP solutions of different concentrations were prepared. By adding $2 \mathrm{gm} \mathrm{SOP}$ to $100 \mathrm{ml}$ water, we can prepare $2 \%$ of SOP solution, and so on this method was used for $4 \%, 6 \%, 8 \%$, and 10\% SOP solutions. The experiment was consisting of following two factors.

\section{Parameters}

To study the influence of SOP and dipping time on germination of pecan nut, the following growth parameters were studied.

\section{Germination percentage}

Germinated seedlings were counted and average was calculated by using the following equation.

Germination $\%=$ No. of total germinated seedling $\mathrm{x} 100$ No. of total seeds sown

\section{Seedlings height $(\mathrm{cm})$}

Seedlings height of pecan nuts was determined with the help of measuring tape by randomly taking 05 plants in each treatment within each replication.

\section{Stem diameter $(\mathrm{cm})$}

Diameter of 05 randomly taken seedlings in each treatment was calculated by vernier caliper at one inch height from the soil surface, and finally their average was determined.

\section{Number of roots}

The numbers of roots plant ${ }^{-1}$ of five randomly taken seedlings in each treatment were counted and their average was calculated.

\section{Root length $(\mathrm{cm})$}

The root lengths of 05 randomly taken plants were determined with the help of measuring tape and their average was calculated accordingly.

\section{Statistical procedure}

The data recorded on different parameters was subjected to analysis of variance
(ANOVA) techniques to observe the difference between treatments as well as their interactions. In case where the differences are significant, the means were further assessed for differences through least significant differences (LSD) test. Statistical computer software, MSTATC (Michigan State University, USA), was applied for computing both the ANOVA and LSD [5]

\section{Results and discussion}

\section{Germination percentage}

The mean data regarding germination percentage is presented in Table 1 .The analysis of variance revealed that the germination percentage was significantly affected by different SOP levels and dipping time, while the interaction of SOP and dipping time showed non-significant effect on germination percentage.

The mean table 1 shows that the highest germination percentage $(70.83 \%)$ was recorded in nuts treated with $10 \%$ SOP solution, closely followed by nuts treated with $8 \%$ SOP $(67.50 \%)$ which was at par with each other. While the lowest germination percentage $(40.83 \%)$ was found in untreated nuts.

Dipping duration for pecan nuts also shows a significant difference for germination percentage. The highest germination percentage $(65.00 \%)$ was recorded in nuts dipped for 10 hours followed by nuts (61.11 $\%)$ which were dipped for 5 hours, whereas the lowest germination percentage $(50.56 \%)$ was recorded in nuts dipped for 20 hours.

Due to hard shell, pecan nuts absorb water in minute amount which is not sufficient for germination. Hence germination stopped or either very low in control which decreased the germination percentage. On the other hand, the germination was increased by priming with SOP, because through priming the seed coat became soft and absorbed water easily. Similar findings were reported in testing the tomato germination percentage that was enhanced significantly when 
Tomato seeds were primed with $2 \% \mathrm{KNO}_{3}$ solution [6].

Table 1. Means comparison of different parameters as affected by Sulfate of Potash levels and dipping time and their interaction.

\begin{tabular}{|c|c|c|c|c|c|}
\hline $\operatorname{SOP}(\%)$ & $\begin{array}{l}\text { Germination } \\
\text { percentage }\end{array}$ & $\begin{array}{l}\text { Seedling } \\
\text { height }(\mathrm{cm})\end{array}$ & $\begin{array}{l}\text { Root } \\
\text { length }(\mathrm{cm})\end{array}$ & $\begin{array}{l}\text { Number of } \\
\text { roots }\end{array}$ & $\begin{array}{l}\text { Stem diameter } \\
(\mathrm{cm})\end{array}$ \\
\hline 0 & $40.83 c$ & $15.11 \mathrm{e}$ & $41.92 \mathrm{e}$ & $53.50 \mathrm{f}$ & $0.52 \mathrm{e}$ \\
\hline 2 & $53.33 \mathrm{~b}$ & $16.76 \mathrm{~d}$ & $46.08 \mathrm{~d}$ & $57.83 \mathrm{e}$ & $0.55 \mathrm{~d}$ \\
\hline 4 & $56.67 b$ & $17.61 \mathrm{c}$ & $49.50 \mathrm{~cd}$ & $61.83 \mathrm{~d}$ & $0.57 \mathrm{c}$ \\
\hline 6 & $56.67 \mathrm{~b}$ & $18.34 \mathrm{c}$ & $53.25 \mathrm{bc}$ & $66.08 \mathrm{c}$ & $0.58 \mathrm{c}$ \\
\hline 8 & $67.50 \mathrm{a}$ & $20.41 b$ & $57.00 \mathrm{~b}$ & $68.83 \mathrm{~b}$ & $0.61 b$ \\
\hline 10 & $70.83 a$ & $22.53 \mathrm{a}$ & $61.67 \mathrm{a}$ & $73.00 \mathrm{a}$ & $0.63 \mathrm{a}$ \\
\hline LSD & 9.33 & 0.74 & 3.84 & 0.99 & 0.0157 \\
\hline \multicolumn{6}{|c|}{ Dipping time (Hours) } \\
\hline 05 & $61.11 \mathrm{ab}$ & $18.27 \mathrm{~b}$ & $55.17 \mathrm{a}$ & $65.00 \mathrm{~b}$ & 0.58 \\
\hline 10 & $65.00 \mathrm{a}$ & $19.04 \mathrm{a}$ & $56.11 \mathrm{a}$ & $69.00 \mathrm{a}$ & 0.59 \\
\hline 15 & $53.89 b c$ & $18.33 b$ & $51.61 \mathrm{~b}$ & $60.89 c$ & 0.57 \\
\hline 20 & $50.56 c$ & $18.20 \mathrm{~b}$ & $43.39 \mathrm{c}$ & $59.17 \mathrm{~d}$ & 0.57 \\
\hline LSD & 7.61 & 0.61 & 3.13 & 0.80 & N.S* \\
\hline \multicolumn{6}{|c|}{ SOP $(\%)$ X Dipping time } \\
\hline & $\begin{array}{l}\text { Germination } \\
\text { percentage }\end{array}$ & $\begin{array}{l}\text { Seedling } \\
\text { height }\end{array}$ & Root length & $\begin{array}{l}\text { Number of } \\
\text { roots }\end{array}$ & Stem diameter \\
\hline & N.S* & Fig: 1 & N.S* & Fig:2 & N.S* \\
\hline
\end{tabular}

*Non significant

Mean \pm standard deviation. Values sharing same letters differ non-significantly $(\mathrm{P}>0.05)$

\section{Seedling height $(\mathrm{cm})$}

Mean data shows that the seedling height of pecan was significantly influenced by different SOP levels and dipping time as well as their interaction. The treatment of SOP solution significantly influenced the seedling height of pecan nuts. The mean data of the Table 1 indicated that the tallest seedling $(22.53 \mathrm{~cm})$ were noted, when the pecan nuts were treated with $10 \%$ SOP solution, followed by the seedling height of $20.41 \mathrm{~cm}$ in pecan nuts treated with $8 \%$ SOP solution. The Pecan nuts in control treatment showed the smallest seedling height $(15.11 \mathrm{~cm})$. Data pertaining to different dipping durations revealed that tallest seedlings $(19.04 \mathrm{~cm})$ were noted when the nuts dipped in SOP solution for 10 hours, followed by the seedling height of $(18.33 \mathrm{~cm})$, when pecan nuts soaked for 15 hours in SOP solution. The smallest seedling height $(18.20 \mathrm{~cm})$ was recorded in pecan nuts when dipped for 20 hours in SOP solution.

Mean data concerning interaction between SOP and dipping time showed significant effect on seedling height of pecan nuts (Figure 1). The data shows that the tallest seedlings $(24.52 \mathrm{~cm})$ were observed in nuts treated with $10 \%$ SOP for 10 hours, while the shortest seedlings $(14.77 \mathrm{~cm})$ resulted in nuts treated with $0 \%$ SOP for 5 hours.

The tallest seedlings in nuts treated with $10 \%$ SOP solution may be due to the earlier germination in these treatments and the seedlings got more time for their growth and utilized more nutrients. Similarly maximum plant height was observed in Gladiolus when 
primed with $3 \% \mathrm{KNO}_{3}$ as compared to those of non-primed[7].

Root length (cm)

The analysis shows that root length was significantly affected by different percentages of SOP and dipping time while their interactions were non-significant.

The treatment of SOP solution significantly influenced the root length of pecan nuts. The data concerning different SOP levels showed that the maximum root length $(61.67 \mathrm{~cm})$ was observed in pecan nuts primed with $10 \%$ SOP solution, followed by nuts treated with $8 \%$ SOP $(57.00 \mathrm{~cm})$, while the shortest roots $(41.92 \mathrm{~cm})$ were noted in nuts soaked in control treatment. The dipping time significantly affected root length. The mean values pertaining to different dipping durations revealed that lengthiest roots $(56.11 \mathrm{~cm})$ were recorded in 10 hours of dipping time closely followed by pecan nuts soaked for 5 hours $(55.17 \mathrm{~cm})$, which was at par with each other. The minimum root length $(43.39 \mathrm{~cm})$ was recorded in nuts having dipping time of 20 hours. The reason for the longest roots of pecan nuts treated with $10 \%$ SOP may be that more number of leaves required more amount of nutrients and water so the plant has to develop its root deeper into the soil in order to uptake more nutrients to fulfill plants need. Lengthier roots in tomato plants were observed when their seeds were treated with potassium silicate at the level of 50 and $100 \mathrm{mg} \mathrm{L}^{-1}$ [8].

\section{Number of roots plant ${ }^{-1}$}

Number of roots plant $^{-1}$ was significantly affected by different SOP levels, dipping time while the interaction of SOP and dipping time had non-significant effect on number of roots plant ${ }^{-1}$. The mean data shows that the SOP solution significantly influenced the number of roots pant ${ }^{-1}$ (Table 1). The mean values regarding various SOP levels shows that the highest number of roots plants ${ }^{-1}$ (73.00) resulted in nuts primed with $10 \%$ SOP solution, followed by nuts primed with
$8 \%$ SOP (68.83). While the least number of roots (53.50) were recorded in untreated pecan nuts.

According to Table 1, the dipping time had significant effect on number of roots plant $^{-1}$. The mean values regarding various dipping durations indicates that maximum number of roots plant $^{-1}(69.00)$ was recorded in nuts soaked for 10 hours in SOP solution, followed by nuts primed for 5 hours (65.00), 15 hours (60.89), and least number of roots (59.17) was recorded in nuts dipped in SOP solution for 20 hours. The mean data pertaining to interaction of SOP and dipping time shows significant effect on the number of roots (Figure 2). The interactive data showed that more number of roots (78.33) was recorded in nuts treated with $10 \%$ SOP solution for 10 hours. While the least number of roots (48.00) was noted in nuts treated with $0 \%$ SOP for 20 hours. The more number of roots might be due to more seedling height and vigor as plants tends to maintain shoot and root balance. In similar studies nutritive media and solutions, containing fulvic and humic acids improved the development of roots of wheat and juwar regards to number, length and mass [9].

\section{Stem diameter $(\mathrm{cm})$}

The analysis showed that stem diameter was significantly affected by different treatments of SOP solutions. However, the dipping time and the interactions between SOP and dipping time have non-significant effect on stem diameter of pecan nuts seedling.

The stem diameter was significantly affected by different SOP levels. The mean Table pertaining to different SOP levels showed that the maximum stem diameter $(0.63 \mathrm{~cm})$ was observed in pecan nuts treated with $10 \%$ SOP solution followed by nuts treated with $8 \%$ SOP $(0.61 \mathrm{~cm})$. While the lowest stem diameter $(0.52 \mathrm{~cm})$ was recorded in nuts primed with control treatment.

The data relating to dipping time had nonsignificant effect on stem diameter of pecan 
nuts. The mean Table shows that maximum stem diameter $(0.59 \mathrm{~cm})$ was recorded in nuts primed for 10 hours duration, while the minimum stem diameter $(0.57 \mathrm{~cm})$ was noted in 15 hours and 20 hours of dipping time. More stem diameter could be due to more seedling height, early germination, seedling vigor and development of number of roots. Researchers observed similar results and reported that more stem diameter was recorded for okra seeds soaked for 24 hours [10].

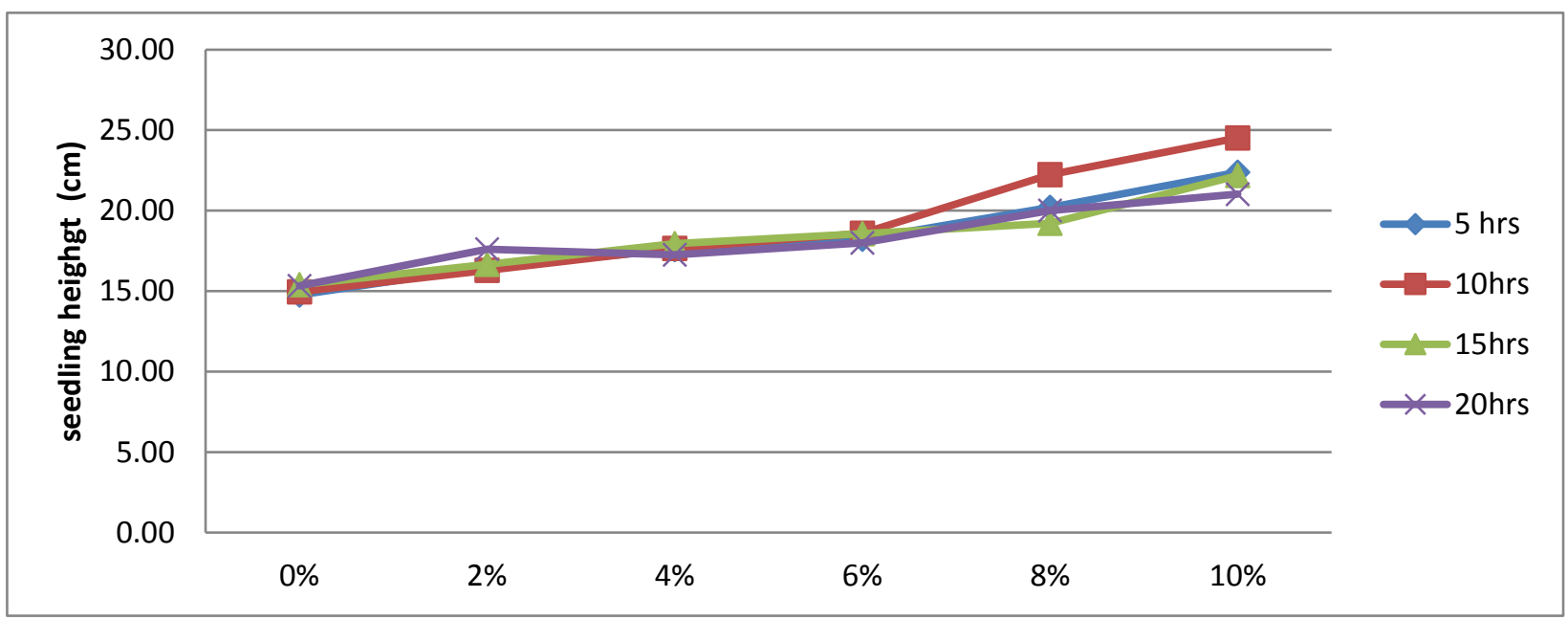

Figure 1. Seedling height of Pecan nuts as affected by sulfate of potash and dipping time

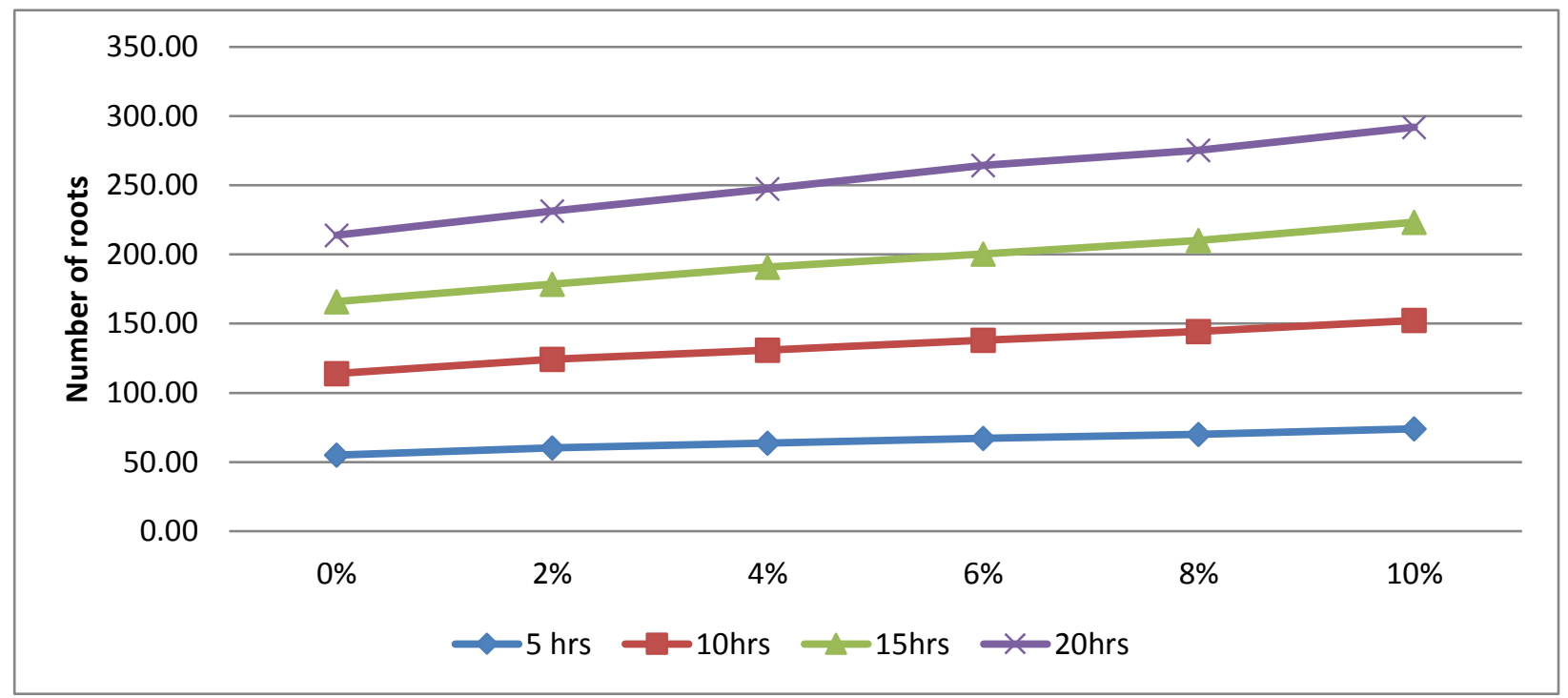

Figure 2. Number of roots of pecan nuts as affected by sulfate of potash and dipping time

\section{Conclusion}

It is concluded that 10 hours of dipping with SOP@10\% gave best seed germination, seedling growth and establishment of pecan nuts plants under agro climatic conditions of Peshawar, Pakistan.

\section{Authors' contributions}

Conceived and designed the experiments: $M$ Sajid\& ARab, Performed the experiments: Z 
Aman, N Ahmad \& QS Ali, Analyzed the data: ST Shah, Contributed materials/ analysis tools: I Hussain \& SM Khan, Wrote the paper: I Hussain \& SM Khan.

\section{References}

1. Westwood MN (1978). Temperate zone pomology. W.H. Freeman and company. New York. USA. p.428.

2. Rehman N \& Jan $T$ (1998). Pecan an emerging nut crop of Pakistan. Pakistan Agriculture Research Centerp.95-97.

3. Moerman D (1998). Native American ethnobotany. Timber Press, Oregon.

4. Welbaum GE, Shen Z, OluochMO\& Jett LW (1998). The evolution and effects of priming vegetable seeds. Seed technology v20(2):209-235.

5. Steel RGD \& Torrie JH (1984). Principles and procedures of statistics, 2nd ed., McGraw Hill Book Co, Singapore.

6. Hamdollah E (2012). Germination and field performance of differentially matured seeds of tomato (lycopersiconesculentum) as affected by seed priming. Intl $J$ of Agric Research and Review 2(6): 857-861.

7. Ramzan A, HafizIA, Ahmad T \&Abbasi NA (2010). Effect of priming with potassium nitrate and dehusking on seed germination of gladiolus (gladiolus alatus). Pak J Bot 42(1): 247-258.

8. Sivanesan I, Son MS, Lim CS \&Jeong BR (2011). Effect of soaking of seeds in potassium silicate and uniconazole on germination and seedling growth of tomato cultivars, Seogeon and Seokwang. Afric J Biotech 10(35): 6743-6749.

9. Rajesh P (2010). Effect of potassium humate and deproteinised Juice (DPJ) on seed germination and seedling growth of wheat and jowar. Ann Bio Res 1(4): 148151.

10. Dumisa KS \&EkpoMO (2011). Impact of Priming Okra (AbelmoschusEsculentusL.) Seeds on Seedling Performance in Swaziland. AdvEnv Bio5(6): 1221-1228. 